\title{
Linking the triple helix (university-industry-government) to the quadruple helix of university-industry-government - civil society in the field of international business and economics
}

\author{
Dumitru MIRON \\ The Bucharest University of Economic Studies, Bucharest, Romania \\ dumitru.miron@rei.ase.ro
}

Ioan Alexandru GHERASIM

Corvinius University of Budapest, Budapest, Hungary

\begin{abstract}
Current educational systems and processes need to anticipate the challenges of the new millennium and lay the foundations for the future in the economic, social, technological, cultural and relational context. New educational programs must seriously consider a number of conditions such as: entirely new ways of serving existing needs and significantly disrupt existing industry value chains; growing transparency, consumer engagement, and new patterns of consumer behavior; the development of technology-enabled platforms that combine both demand and supply to disrupt existing industry structures, such as those we see within the "sharing" or "on demand" economy. In this paper I've started from the assumption that in the specific conditions of a creativity-based economy is necessary to rethink the components of the matrix partnership crossing from 'triple helix' to 'quadruple helix' logic. This new model becomes necessary because under current regional and international circumstances Mode 3 of knowledge production has become generalized. In this paper I've opted for the concept that adds civil society proposing reformulate the analytical model so as to place in balance integration with differentiation to produce suitability for a societal design defined by the self-organization of the sense communication process with respect to the analytical axes of complex systems. The basic idea of the research is to identify the way in which the challenges of internationalization of education, the transformations required by the emergence of this process, and the most relevant redefining that must take place at the level of curricular architectures and learning methods are understood. Based on the research I have made, I recommended few ways to cope with sensitive challenges educational systems are confronted with such as: better connecting theory and practice, teaching a more useful economics, designing the future based on the understanding of the past, minimizing the rhetorical component and maximizing the factual one, testing conformity of different ideas in advance.
\end{abstract}

Keywords: quadruple helix; triple helix; creative economy; modern education; curricular design.

\section{Introduction}

The characteristics of a society based on creativity underlines the importance of the helix logic in understanding the mechanisms of the progress of contemporary education obliged to cope with few paradigms shift. Current educational systems and processes need to anticipate the challenges of the new millennium and lay the foundations for the future in the economic, social, technological, cultural and relational context. New educational programs must seriously consider a number of conditions such as: entirely new ways of serving existing needs and significantly disrupt existing industry value chains; growing transparency, consumer engagement, and new patterns of consumer behavior; the development of technology-enabled platforms that combine both demand and supply to disrupt existing industry structures, such as those we see within the "sharing" or "on 
demand" economy. Educational systems of the future have to turn from being part of the problems into architectures which offer solutions to the problems and, before seeking answers, ask intelligent questions. One of the most challenging question to be answered in What should it mean to be an Educated Person in the 21st Century? Trying to answer this question one author (Robinson, K. 2001) identified the following challenges:

- The economic challenge is to develop in young people the skills, knowledge and personal abilities they need for a world where work is undergoing rapid and longterm change. Economies increasingly depend on the ability of individuals and organisations to generate new ideas. This is true in special in the creative industries - advertising, architecture, arts and antiques, crafts, design, designer fashion, film, leisure software, music, performing arts, publishing, software and computer services, television and radio - which offer rapidly growing opportunities for young people.

- The social challenge is to provide forms of education that enable young people to engage positively and confidently with far-reaching processes of social and cultural change. The Education provided in most countries does not do this. The combined effects of economic and technological change are transforming the social landscape. Communities must cope with the decline in traditional types and patterns of work, and the growth of new employment opportunities.

- The personal challenge is to develop the unique capacities of all young people, and to provide a basis on which they can build lives that are purposeful and fulfilling. The majority of young people have positive attitudes towards school. But a growing number question the value of education. Truancy and disaffection are acute among those who underachieve, and whose cultural values and identities conflict with those of the schools they attend or the areas where they live. One effective solution to this is to develop active forms of learning which engage young people's creative energies. The trend is to freelance work, short contracts, self-employment, and entrepreneurial ability. The impact of these changes is global and cuts across national boundaries.

- The technological challenge is to enable young people to make their way with confidence in a world that is being shaped by technologies which are evolving more quickly than at any time in history. New technologies offer young people unprecedented opportunities to broaden their horizons; find new modes of creativity; and deepen their understanding of the world around them. But is mandatory that universities transform their methods of teaching and learning.

The main hypotheses of the author were: in a creative economy, all societal actors must radically rethink their prospects of success determinants; the complexity of the current economic, social, technological and cultural landscape requires the integration of the efforts of all categories of interest groups; the logic of the spiral triangle is no longer appropriate to capture the circularity of the transformations that are produced, adding new spirals (in the present case of the civil society-specific); the most precious factor of development and sustainability is no longer capital but talent and attitude; educational processes are called to provide skills, cognitive skills and attitudes.

The main questions the author attempted to give as much as sustainable answers were: 
How can teaching and education change or does it have to? What is the essence of 21st century learning? Is incorporating all technological innovations into the physical classroom the methodology of choice? Is that even possible or affordable? What do we mean by emotional "intelligence"? What impact would improve emotional intelligence have on learners' emotional health and well-being, academic achievement, and other adaptive outcomes? Can emotional intelligence be taught? Can academic institutions find the structural and financial means to encourage its emergence, sustain it and recognize its socioeconomic usefulness, as well as to foster its development and the teaching of its outcomes? How do we get beyond the paradox of institutions, created for the purpose of transmitting knowledge, encouraging the challenging of such knowledge?

\section{Literature review}

We are witnessing an authentic revolution that occurs at all levels of education landscape. Widespread digitalisation will bring about significant changes in the skill-sets needed from the labour force (Hadad, 2017). As Gibbons mentioned "... the First Academic Revolution was about adding the function of research to the two other functions of the university, that is preserving and transmitting knowledge. By contrast, the second revolution considers another major change in the mission statements of universities, a change that would make participation in the process of economic development into a core value (Gibbons, 2000). Recent projections published by the European Commission show that in the years up to 2025 , about half of the jobs will require high-level qualifications, while $65 \%$ of children entering primary school now will be working in occupations that do not yet exist. In this context, all societal actors need to understand that is essential to appropriately manage the following challenges: passing from a "knowledge-based economy" to a "creativity-based economy"; switching from a capital and labor-intensive economy to one where the main factors become entrepreneurship, talent stock and people's attitude; switching from markets to networks (where the global value chains are prevalent); synergic management of the "green economy, blue economy, and the "orange economy,; coping with new means of communication, new ways of differentiation, new methods of exchange and accumulation, new modalities of moving assets, new ways to make things happen and a sensitive chain of news - new materials, new products, new processes, new attitudes.

As European citizen`s desire is to prosper and thrive in increasingly competitive and knowledge-based environment one need to ask if Romanian universities are appropriately equipped to support this new trends. To answer to this challenge we need to take into consideration that:

- Technology progress enables the redesigning of production and consumption systems in order to increase efficiency, but also endangers jobs because of robotics and other innovations;

- Frequently are developed new and sophisticated business models using computers, enabling scientific analyzes and forecasts as well as spreading information provided by manufacturers and traders but there will not be enough specialists to implement exponential technologies;

- The manufactures are producing more efficient, greener, safer and smarter goods but all revolutionary technologies narrows labor demand and imposes new requirements for education; 
- Every individual will benefit of impressing opportunities but need to acquire a stock of knowledge which is not quantitative but specialized and qualitative, focusing on the future demands;

- Mobility is becoming more and more important and hyper-connectivity is making the location of work irrelevant but become mandatory structural reforms in labor markets by removing barriers and bureaucracy, by simplification of regulations, by reducing taxes on labor, by boosting education and training, by supporting entrepreneurship and startups.

As Klaus Schwab mentioned (Schwab, K. 2016) „We must develop a comprehensive and globally shared view of how technology is affecting our lives and reshaping our economic, social, cultural, and human environments. There has never been a time of greater promise, or greater peril." The Fourth Industrial Revolution has important effects in all aspects of human society (public authorities, the economic and social environment, education systems, society as a whole). This paradigm shifts influences us in all the hypotheses we relate to: as customers, as products and services providers, as attendants to collaborative networks, as designers of societal structures and as individuals. As Robert Shiller said, we cannot wait "until a house burns down to buy fire insurance on it. We cannot wait until there are massive dislocations in our society to prepare for the Fourth Industrial Revolution.". Between the most challenging questions mandatory to be asked we suggest to reflect on: How can teaching and education change or does it have to? What is the essence of 21st century learning? Is incorporating all technological innovations into the physical classroom the methodology of choice? Is that even possible or affordable?

A report published by the Global Schools Leadership Alliance (Moving Forward, 2016) states the following: „education is failing to prepare young people for their working future; young people need to develop right-brain skills (creativity) just as much as left-brain (mathematics and technical) to adapt to the emerging economy; employers need to take charge of training employees, providing full-time rather than part-time positions, and provide them with adaptive skills in the face of disruptive change; liquid skills and continuous learning are needed to address future work; digital tools need to be embraced by educators and employers to let young people teach themselves anything they need to achieve success; disruptive innovation awareness must be the guiding principle behind education to ensure adaptability to change; speed and ubiquity of change must be front of mind in the development of all educational strategies,.

In another relevant international document (Human Capital Report, 2017) we find the idea that "How nations develop their human capital can be a more important determinant of their long-term success than virtually any other factor." The correctness of this assertion is based on the fact that: students will interact with others remotely; the success of learning processes will rely on different skilled teachers; the diploma will have a different meaning; everybody will have forced to adapt.

Ken Robinson (2001) feels schooling has focused too much on acquiring knowledge, rather than nurturing emotions, passions and interests that can be accomplished by better integrating the arts into a liberal education. Robinson suggests a need to re-evaluate the relationship between the sciences and arts and how the two interact with each other. The Sciences are thought to be about knowledge, facts and objectivity. This means that decisionmakers cannot meet the challenges of the 21st century with the educational schemes of the previous centuries. Another analyst (Darling-Hammond, L. 2010) states that the new 
mission for education should be to prepare students to work at jobs that „do not yet exist, creating ideas and solutions for products and problems that have not yet been identified, using technologies that have not yet been invented,. Daniel Goleman (2013) refers to soft skills as "Emotional Intelligence". People that are emotionally intelligent are self-directed, highly motivated and have excellent communication skills. Modern education systems need to prepare answers to such questions as: What do we mean by emotional "intelligence"? What impact would improve emotional intelligence have on learners' emotional health and wellbeing, academic achievement, and other adaptive outcomes? Can emotional intelligence be taught?

\section{Linking the „triple helix,, to „quadruple helix,, in the process of reforming education in Romania}

Some specific characteristics of the „Triple Helix,,

The "Triple Helix" model can be defined as a partnership for knowledge and, consequently, may exercise a main role in the future development of the knowledge society. (Miron, D. 2008) This model integrates the actors from research, from business and government. (Etzkowitz, 2002). In the first category one can involve universities which conceive their educational programs oriented towards training the new competences of the future graduates. The second category is formed by the actors from business environment who have the capacity to realize the economic importance of the new developments in knowledge, to foresee the demands on the market, to assume the opportunities and the risks in applying the new technological solutions as well as to initiate and run business projects. The third category is made up by the governmental decision making bodies which establish conditions for the functioning of businesses, of research centers and universities, deploy public funds for research and development and facilitate the setting up of new companies and look after citizens' welfare.

The "Triple Helix" Model presents specific advantages for each of the three categories of the involved actors. Thus the application of the model by businesses and industries helps expand long term and risky research activities to experts in the field; obtain proprietary technology through licensing; agreements; leverage funding through matching grant projects; collaborating research labs are source of new recruits.

In a creative based society become a natural phenomenon to promote mutual learning among the three actors with a view to creating a friendly interface during their interaction. Research consortia get companies and universities together to help promote a common theme. The teaching staff offer consultancy to companies while the companies cofinance projects together with universities. From companies, universities learn what entrepreneurship means. In their turn companies learn from universities both how to train their own employees and even their customers and how to manage knowledge. The interaction area among universities and industries mainly includes technology parks, innovation clusters, business incubators, mixed academy-industry research centers and spin-offs. For universities and research organizations the adoption of the Triple Helix Model could ensure: additional sources of funding with industry and government sharing the load; allowing for critical mass of personnel and in general more efficient research; training of highly qualified personnel in industrial related research good for job placements; removing stigma of "ivied walls"; encouraging research projects based on strategic needs with long 
range benefits to the community. For governmental bodies the interaction with the industry and the academic environement could contribute to the following goals: creating an economic climate that generates economic growth and new jobs; welfare benefits from taxes and duties; promoting strategic R\&D initiatives; improving the quality of life and the level of citizens' satisfaction.

The main conceptual weakness of the "Triple Helix" Model highlighted by its critics refers to the significant differences between the system of regulations on the basis of which the industrial, academic and government entities function. Thus, companies practice a logic of the equivalent exchange while universities - one of non-equivalent exchange. There are also differences among the decision making systems and practices: each category of actors operates with rules, criteria and decision making methods determined by their institutional characteristics. Could be difficult to create a framework in which synergy can be generated through the actions and interactions of governmental officers, having a limited mandate and functioning within more or less bureaucratic institutional structures, representatives of the economic environment, with their fundamental interest of profit maximization and members of the academic community, concerned more with ideas, innovation and latest methodologies and then being acquainted with the regulations of public institutions and the specific constraints of the business world. Some authors (Brännback et al. 2008), considered that the model coul be unsuccessful because the entrepreneurs (full of initiative, organizationally structured and having the decision making mechanism) and the innovators (scientists from the academia, researchers) have been unwilling to also associate the governmental actors as well therefore wasting valuable synergetic potential. As far as the role of the state as sponsor continuous to decrease there is the risk, particularly in applied research, that the contract stipulations limit the role of universities in the dissemination of knowledge. One of the solutions could be the deploying public resources towards applied research within a framework that allows the dissemination of results towards companies but also the use of results in the training activities by universities.

The "Triple Helix" Model mainly promotes the partnership among consolidated structures (government - businesses - academia) explicitly non-integrating the smaller or the individual actors with the implicit understanding that these latter ones have fewer chances to promote this philosophy. The studies of Zucker et al. (1998 and 2002) have shown that if small businesses are located in the neighbourhood of important, prestigious scientific institutions they are more successful. At the same time, scientists working in the proximity of innovative companies become more peformant and get publicity at an earlier stage in their careers due to the fact that they receive messages from the economic environment more rapidly and, thus, need to face challenges and to solve specific problems. The applicability of the patterns of triple helix model becomes more sustainable as become more important the 'third mission' of a university - involvement in socio-economic development, next to the traditional academic missions of teaching and research considered as a "second academic revolution" (Etzkowitz, 2006).

\section{"Quadruple Helix,, model}

In the specific conditions of a creativity-based economy, some of the model-specific elements described above are provocative transformations and require the rethinking of the components of the matrix partnership. This new register in which the current societal picture should be rethought is closely related to the advancement of innovation processes. 
The emergence of this new model is in tune with the process of passing linear to systemic, open and user-centric innovation models. In the literature there is a wide range of perceptions on the "quadruple helix, models. Some of them are very close to the "triple helix, concept, some of them deviate more radically from it and many of them are somewhere between these two extremes. In this paper I use the „quadruple helix, model concept as a synergic extension of the previously presented one ("triple helix,") adding a fourth dimension. Some authors (Liljemark, T. 2004) consider that these fourth actors are innovation-enabler organizations acting as brokers and networkers between the other organizations. Thera are some analysts who appreciate that the fourth component of the model should be the international dimension. Yawson (2009) consider that another candidate as the fourth helix is the user of knowledge that is the public. This choice is supported by the opinions brought forward in recent innovation research and policy, which present user-driven innovation as an essential factor of success for both firms and public sector organizations (Eriksson et al. 2005, Lundvall et al. 2002, Thomke \& von Hippel 2002, Schienstock \& Hämäläinen 2001).

The quadruple spiral model becomes necessary because under current regional and international circumstances Mode 3 of knowledge production has become generalized. As some authors (Carayannis, E.G. Campbell, D.F.J. 2012) mentioned, the Mode 3 Knowledge Production System architecture focuses on and leverages higher order learning processes and dynamics that allow for both top-down government, university, and industry policies and practices and bottom-up civil society and grassroots movements initiatives and priorities to interact and engage with each other toward a more intelligent, effective, and efficient synthesis. In so doing, Mode 3 ensures a tighter and more robust coupling of vision with reality and helps reify the socio-economic and socio-political being and becoming by achieving between aspirations and limitations.

In this paper I've opted for the concept that adds civil society, starting from the assumption that we will be the inhabitants of a society that will no longer be coordinated by central institutions but will rely on interactions between different coded communication networks. The most important drivers of new type communication are: money; power, faith, trust and affection (subjective preferences). The new model of development should be reformulated so as to place in balance integration with differentiation to produce suitability for a societal design defined by the self-organization of the sense communication process with respect to the analytical axes of complex systems. The essence of the new societal model in relation to which national education systems should be rethought is the concepts of creativity and economics of creativity. In the most common way, a creative economy can be defined as: an economy that more efficiently use new drivers of growth; an economy where the sources of generating sustainable competitive advantages have changed significantly; an economy inscribed in the new logic of sustainability (economically efficient, socially responsible and promoting the concern for ecological balances).

Sustainability does not mean adding value to the three dimensions, but to systemic analysis, integration and holistic thinking." (Gladwin, Thomas, James Kennelly, and TaraShelomith Krause, 1995a). In this respect:

$\checkmark$ Eco-efficiency is a complex concept that is placed at the confluence of economic and ecological sustainability. Even if we find many definitions of this concept, those that are most widely accepted in the literature are those that advocate for the simultaneous attainment of economic and ecological desiderata; 
$\checkmark$ Social productivity - lies at the confluence of economic and social sustainability. And in connection with this concept, we find a great diversity of approaches. It is often said that "a successful business is an ethical business." More and more lately there are talks about terms such as social responsibility or credibility.

$\checkmark$ There is also the third couple of terms combining social and ecological sustainability. One can speak here of the term "sufficiency" deriving from the answer to the question of what level of consumption can be sustained without subjecting unbearable pressures to limited resources. It opens up what the specialists have called the "ethical dilemma." This concerns the situation where sustainability does not necessarily mean just profitable.

Creativity is the most important way towards innovation, an essential prerequisite for new and performant education and training schemes especially in a world where competitiveness becomes the most important societal asset. As many scientists mentioned, creativity need to be identified, recognized and stimulate. These are now, but especially in the future, the vital objectives of the new educational processes. Increasing the ability to learn how to learn is not enough, and we need to focus on learn how to unlearn too. One of the most important goals of new education is to increase the level of intensity in creativity at the level of curricula and syllabus. The most sensitive challenges to which all involved in educational landscape must identify appropriate solutions cold be: Can academic institutions find the structural and financial means to encourage its emergence, sustain it and recognize its socioeconomic usefulness, as well as to foster its development and the teaching of its outcomes? How do we get beyond the paradox of institutions, created for the purpose of transmitting knowledge, encouraging the challenging of such knowledge?

Generating creativity is a proactive process and for this reason all societal actors need to understand its potential consequences and exploit them. Creativity does not cope with rigid societal structures makes light of inertia and is opposed to conservatism. Being creative means that instead of doing things better we will have to learn to do it differently.

Those who are involved in the process of reforming education systems to be prepared to provide proactive solutions to challenges related to the creative economy must take into account the opportunities and threats that are attached to it. Creativity is a very complex phenomenon. The main characteristics of this very sensitive phenomenon are: creativity is a solitary process, not a collective one; creativity is not a continuous process, filling every instant; creativity is an opportunist activity, resistant to the kind of evaluation applied to knowledge, as distinct from cognitive behavior; creativity is most likely to emerge in loosely formed structures that are labile and reticulate rather than hierarchical, structures such as the networks that are beginning to sprout here and there. New education systems must take into account the following objectives: to seek out what characterizes creativity; to analyze the role played by creativity in the processes of discovery and invention; to restore the relationship between creativity and behavior, creativity and skills, and creativity and social trust; to examine how the nature of creativity can be transmitted and to teach how its outcomes can be exploited; to explore ways of detecting the qualities inherent in creativity and developing them; to determine how the creative process will change in the new century.

Among the opportunities related to creative economy can be mentioned: there are still prerequisites for raising income levels and increasing the quality of people's lives; the possibility of a technological-oriented miracle biased towards the supply side is created to 
support the advancement of both productivity and efficiency; it is assumed that the generalization of regional and global value chains is expected with new organizational architectures and new people's behaviors; we can redefine the concept of secure and well paid jobs; uncertainty can become great; the most valuable production factor can become talent.

Among the threats related to creative economy can be mentioned: the deepening of inequalities; increasing the level of fragmentation of the human capital market; the deepening of social discontinuities; advancing the precarious state at the level of the balance between remuneration of labor and capital; changing too fast the balance between tangible (real) and intangible (intangible) assets; inability to manage the challenges posed by exponential developments in the economy and society; increased risk of believing that ignoring reality can also be avoided by the effects of this attitude); volatility of the new generation of the international capital market, technology and commercial information.

\section{Some changes in the educational landscape and specially in the curricular design}

We live fascinating times in which the landscape of societal actors constantly changes, the balance of power between them is redefined, cooperation and confrontation are present and dominant logic is always different. In both the competitive and the rivalry process, all participants in this game are attracted (governments, corporations, social movements, nongovernmental organizations, cross-border flows and many other social forms). Yet even if our endowments are growing and our classrooms are filled with eager students, those of us who teach economics and business or public policy and international affairs have no reason to be complacent because it's not clear we're doing the best job we could.

There is a very frequent talk about the internationalization of education (Ghinea et al., 2017). At least in our country, unfortunately, the perception of the university environment about what it really means is quite restrictive. As one of the experts involved in an international project that had as main objective the counseling of 20 Romanian universities in order to better understand the process of internationalization and the elaboration of some internationalization strategies and strategic lines at national level in this field, I have found that internationalization is reduced either to cross-border mobility programs of the members of the university communities or to the promotion of study programs offered in international languages. The least is the internationalization of curricular designs. It is true that some disciplines are international by their very nature such as international relations while the international element may be less apparent in other domains. This should not lead us to a defeatist attitude that prevents us from seeking ways of modernization in curricular terms and for these disciplines. At international level, awareness of this need is increasingly evident. This defining desideratum for the modernity of educational systems is found in some reports of some international associative architectural profiles in the following form "the process of equipping students with the knowledge and understanding, skills and attributes needed to work and live in a way that safeguards environment, social and economic wellbeing, both in the present and for future generations, (QAA and HEA, 2014). In the literature, we find a multitude of definitions of curricular internationalization. one of them is that according to which "A curriculum with an international orientation in a content and/or form, aimed at preparing students for performing (professionally/socially) in an international and multicultural context and designed for domestic and/or foreign students." (OECD, 1996) Internationalization involves provision of curricula, pedagogies and assessments that foster an understanding of national 
and global perspectives and enables reflection on how these diverse views intersect with students' personal perspectives. The dynamic evolution of the European Union recognized the need to provide a harmonized educational system able to provide smooth mobility of students and professors, international projects and collaboration, support for any attempt to internationalize the educational activities and finally to build an European identity among the students (Dima and Vasilache, 2016).

PICBE $\mid 621$

Internationalization at the level of curricular design does not mean the mimetic take-up of some disciplines from the curricula of prestigious foreign universities but the signaling of the fact that students are willing to be prepared for an international economy and society in which regionalization and globalization are present. It must be understood and accepted at all levels of the educational process that curricular internationalization necessarily implies: course and unit contents must to appropriate reflect diverse local and international perspectives on economic, political, environmental, social, ethical and health issues of global significance; commuting from teaching to learning for educational strategies to become culturally inclusive, support diverse modes of learning and engage local students appropriately with international students; instructional materials, media and resources should have diverse authorship and cultural origin and optimize the development of global perspectives; assessment strategies should measure the skills, knowledge and understanding associated with global and intercultural perspectives.

After joining European Union in 2007, Romania has to go from a conformationbased attitude to one based on proactivity. This paradigm shifts also need a fundamental change in the perspective of studying international economic relations as a background element of curricular design, not only in specialized studies, but also in most other curricula. This change of perspective is imposed by the transformations that take place at the level of power balances, not only in the political field but especially in the economic one. Power was passing almost imperceptibly from the geopolitical level to a geo-economical one, from bankers and lawyers to full-time foreign-policy experts. Like in many other countries, and in our country, maybe especially in our country, experts in foreign policy are nor selected based on their expertise but also for their political affiliations, reputations, personal connections, and loyalty for some interest's groups. This attitude of public policy decision makers deepens the process of deprofessionalizing the body of specialists in the area of promoting the interests of our country, discourages young people from opting for university studies programs specialized in international economic relations and can contribute to the decoupling of the Romanian economy and society of the major transformations that are announced at regional and international level. Developing and delivering curricular designs in the field of international business and economics, of the highest quality that promote internationalization and can contribute to the reprofessionalization of the body of experts in promoting Romania's vital interests may be the ground where the logic of "quadruple helix , can be applied. In this area, concerted efforts are needed both by public authorities and universities, but also by the corporate environment and civil society.

The understanding by all those interested in the advantages offered by the synergic approach of the four helixes and the avoidance of the vulnerabilities that we highlighted in this paper are preliminary conditions for redesigning the curricular designs of the Romanian schools of international business and economics. To do that in the most 
performant manner based on my practical experience and on points of view very well explained in literature, I recommend the following measures:

$\checkmark$ Better connecting theory and practice. Without a very solid theoretical background, the best universities can do is extrapolate from present conditions. It must be understood, however that connecting theory to practice and showing how it can illuminate and clarify different choices isn't easy. Became mandatory that learners are obliged to keep searching for better ways to impart the simple analytical tools and capacity for critical thinking that future leaders need.

$\checkmark$ Teaching a more useful economics. Academic experts in this field are very performant at teaching their professional canon: the theory of comparative advantage, the basic principles of international finance, and the growing body of literature on development. Unfortunately, they aren't as good at teaching the actual mechanics of the international economic and financial order and exploring the connection between geo-economics and geo-politics giving to students the appropriate tools for understanding how each affects the other.

$\checkmark$ Designing the future based on the understanding of the past. Teaching disciplines such as the history of diplomacy, the history of the world or national economics, economic and political theories and doctrines is essential to understand the complex phenomena that take place in long-term horizons and what remains and what needs to be abandoned. Unfortunately, for reasons related to the so-called curricular rationality, poorly understood, these disciplines have been removed from the curricula of most of the faculties by depriving students of a rich treasure of knowledge. Students need to understand that history isn't just a collection of names and dates, but also a set of competing, overlapping, but still distinct narratives. The past need to be interpreted, debated, and constructed for us by historians of various kinds and by society as a whole. Different people do not see the past in the same way and thus do not see present problems in the same light. As some author mentioned (Walt, M.S. 2018) the problem is not „about being "politically correct” or "culturally sensitive”; it's recognizing that if your goal is persuading someone to do what you want, it's essential to know where they are starting from and what misconceptions you'll need to overcome,..

$\checkmark$ Minimizing the rhetorical component and maximizing the factual one. Several levels of "quadruple helix", especially those of public authorities, operate with slogans such as "education is a national priority", or similarly sound but when we look at what is actually done to modernize and finance this a vital sector of society, we find a lot of lagging behind of facts comparing with rhetoric. Almost everybody talks about strategies, public policies, national programs, numerous activities and measures but nobody does some specific actions to improve it. At the quantitative level, we cannot say that in Romania no reform programs or strategies have been announced to improve the various facets of the education process. What can be reproached to all societal actors is the lack of coherence and consistency, the insufficiency or lack of impact studies, the unprofessionalism of those who have to implement the regulatory and institutional framework taken from the experience of more developed countries. In other words, thinking strategically requires a sense of the "big picture" and a clear idea of how actors, trends, and problems fit together.

$\checkmark$ Testing conformity of different ideas in advance. It is increasingly clear that neither the future cannot be built with the instruments of the past nor the future curricular 
architectures can be almost identical replicas of current ones. We are currently witnessing the transition from markets to networks, from disparate actions to global value chains, from international politics to global governance. All this requires other types of educational software, teachers who understand precisely these transformations and an economic environment but also a militant civil society, open to the external environment and willing to demand active participation in the decisions taken in the economy but also outside it. Become mandatory for students to learn from specialists who care about real world and for people who have appropriate experience in the professional landscape they expect to be involved. It is mandatory for schools of international business and economics to devote more interest to explain different the conventional wisdom. It will be necessary to promote interactivity and transdisciplinarity so that students can see how the same phenomenon is experienced by specialists from different fields, can learn not only from academic staff but also from others, they can have different perspectives on the same phenomena and processes, focusing especially on the causes for which they manifest in one way or another

\section{Conclusion}

Helix logic has the advantage of grounding evolutionary processes that are no longer linear but fall into the logic of virtuous circles, allow the clarification of arguments and effects, and synergy between multiple plans. In this paper I presented the synergic interference between four essential societal plans: the governmental plan, that of education and research, the corporate and the civil society.

It is more than obvious that Romania must urgently go to other dominant logic types: from conformity to proactivity, from accession to integration into the European Union and from disciplinary to trans-disciplinarity. At the level of the whole educational system of our country, we must fully understand that the new Europe is being built on an individual level and not on a collective level. That is why another curricular design and other learning methods become mandatory.

Because radical transformations take place at the level of the human capital market, it is imperative that the reforms that take place at the educational level can adequately respond to the question How can Romania prepare its workers for the jobs of the future? Because we witness fundamental changes in the labor market, all actors in the quadruple helix logic have to make these transformations timely and act concertedly to find solutions to the new challenges. Some actors of the quadruple helix seem better prepared than others. For instance, growing interest among companies in investing in fields such as artificial intelligence, machine learning, 3D printing, robotics, automation and data processing, mean that we can imagine that Romania will have enough new job opportunities for young people. The most pressing challenge is to up skill the existing workforce and prepare the future workforce with the skill sets needed to be a part of the disruptive industries of the future.

It must be understood throughout the quadruple helix chain that the success of tomorrow depends on the sustainability of the measures we take today, opening, proactivity, creativity and bending to work. 


\section{References}

Bengt-Åke, L, Johnson, B. Sloth Andersen, B. Dalum, B (2002) National systems of production, innovation and competence building. ELSEVIER. Research Policy 31 (2002), 213-231

Boardman, C., Gray, D. (2010). The new science and engineering management: cooperative research centers as government policies, industry strategies, and organizations. Journal of Technology Transfer 35, 445-459.

Brännback, M., Carsrud, A., Krueger, N., Elfving, J. (2008). Challenging the Triple Helix model of regional innovation systems: a venture centric model, International Journal of Technoentrepreneurship, special issue on "Financing Biotech companies", forthcoming.

Carayannis, E. G., Campbell, D. (2011). Open Innovation Diplomacy and a 21st Century Fractal Research, Education and Innovation (FREIE) Ecosystem: Building on the Quadruple and Quintuple Helix Innovation Concepts and the "Mode 3" Knowledge Production System. Journal of the Knowledge Economy 2 (3), 327-372 (http://www.springerlink.com/content/ d1lr223321305579/).

Carayannis, E. G., Campbell, D. (2012) - Mode 3 Knowledge Production in Quadruple Helix Innovation Systems Twenty-first-Century Democracy, Innovation, and Entrepreneurship for Development. Springer Briefs in Business 7, DOI 10.1007/9781-4614-2062-0_1,

Darling-Hammond, L. (2010) - The Flat World and Education. New York: Teachers College Press.

Dima, A. \& Vasilache, S. (2016). Trends in the internationalization of European higher education in a convergence perspective. Management \& Marketing, 11(2), pp. 449457. Retrieved 25 Feb. 2018, from doi:10.1515/mmcks-2016-0008

Eriksson, M., Niitamo, V-P. \& Kulkki, S. (2005). State-of-the-art in utilizing Living Labs approach to user-centric ICT innovation - A European approach. Retrieved from http://www.vinnova.se/upload/dokument/Verksamhet/TITA/Stateoftheart_Living Labs_Eri ksson2005.pdf on 12 August 2009.

Etzkowitz, H. 1993. Technology transfer: The second academic revolution. Technology Access Report 6, 7-9.

Etzkowitz, H. Leydesdorff, L. (1998).The endless transition: A "triple helix" of universityindustry-government relations. Minerva 36, 203-208.

Etzkowitz, H., and Zhou, C. (2006). Triple Helix twins: innovation and sustainability, Science and Public Policy, volume 33, number 1, pp 77-83.

Ghinea, V. M., Dima, A. M., \& Hadad, S. (2017). EXCELLENCE MODEL FOR SUSTAINABLE CONVERGENCE IN THE EU HIGHER EDUCATION. Amfiteatru Economic, 19(11), 1107-1122.

Gibbons, M., Limoges, C., Nowotny H., Schwartzmann, S., Scott, P. and Trow, M. 1994. The New Production of Knowledge, Sage.

Gladwin, T. Kennelly, J. Tara-Shelomith, K (1995) - Shifting Paradigms for Sustainable Development. Implications for management Theory and Research. The Academy of Management Review, Vol. 20, No. 4 (Oct., 1995), pp. 874-907.

Goleman, D. Richard, E. Boyatzis, A (2013) - Primal Leadership: Unleashing the Power of Emotional Intelligence. Harvard Business Review Press. 2013. 
Hadad, S. (2017), "Strategies for developing knowledge economy in Romania", Management \& Marketing, Challenges for the Knowledge Society, 12(3), 416-430. DOI: 10.1515/mmcks-2017-0025.

Leydesdorff, L. (2008). Configurational Information as Potentially Negative Entropy: The Triple Helix Model. Entropy 10, 391-410.

Liljemark, T. (2004) Innovation Policy in Canada. Strategy and Realities. Swedish Institute for Growth Policy Studies. Stockholm.

Miron, D. (2008) Linking the double helix of learning and work to the triple helix of university-industry-government in the Europe of knowledge, Management \& Marketing (2008), 3(4), 3-20.

Robinson, K. (2001) Out of Our Minds. West Sussex: Capstone Publishing, 2001, p. 155.

Schienstock, G. Hämäläinen, T. (2001) Transformation of the Finnish innovation system: A network approach. Sitra Report Series. January 2001.

Schwab Klaus (2016)The Fourth Industrial Revolution. World Economic Forum. Geneva Switzerland.

Thomke, S. von Hippel, E. (2002). Customers as Innovators: A New Way to Create Value. Harvard Business Review.

Walt, M.S. (2018) America's IR Schools Are Broken. There's a lot of innovation on the surface, but the rot runs deep. Here's how to fix it. Foreign Policy. $20^{\text {th }}$ of February 2018.

Yawson, R. M. (2009) The Ecological System of Innovation: A New Architectural Framework for a Functional Evidence-Based Platform for Science and Innovation Policy. The Future of Innovation Proceedings of the XXIV ISPIM 2009 Conference, Vienna, Austria, June 21-24, 2009.

Zucker, L. Darby, M. Amstrong, J.S. (2002) Comercializing Knowledge: University Science. Knowledge Capture and Firm Performance in Biotechmology. Management Science. 48 (1). 2002.

Zucker, L. Darby, M. Brewer, M. (1998) Intelectual Capital and the Birth of U.S. Biotechnology Enterprises, American Review. 88, 290-306. 